\title{
Evaluation of the measurement capabilities of an high performance commercial high resistance bridge by means of the comparison with two validated high resistance measurement methods
}

\author{
F. Galliana ${ }^{1}$, P.P. Capra ${ }^{2}$ and E. Gasparotto ${ }^{3}$ \\ ${ }^{1,2,3}$ National Institute of Metrological Research, strada delle Cacce 91, 10135 TURIN - Italy \\ 1 +390113919336,f.galliana@inrim.it \\ 2+390113919424, p.capra@inrim.it \\ +390113919425, e.gasparotto@inrim.it
}

\begin{abstract}
Resumé. À l'Institut national de la métrologie de recherche (INRIM) ont réalisée une comparaison de mesure entre un pont de mesure de haute résistance électrique commerciale et deux méthodes de mesure de haute résistance électrique validée utilisé à l'INRIM. Ils ont procédé à une estimation de l'incertitude de mesure du pont à partir de $10 \mathrm{G} \Omega$ jusqu'à $10 \mathrm{~T} \Omega$. Quatre étalons de haute résistance de haut niveau à partir de $10 \mathrm{G} \Omega$ jusqu'à $10 \mathrm{~T} \Omega$ ont été calibrés avec les trois méthodes de mesure. La compatibilité de ces mesures était bon. Quelques problèmes pour les mesures plus de $10 \mathrm{~T} \Omega$ et dans l'évaluation de l'incertitude de mesures du pont, cependant, restent en suspens.
\end{abstract}

\section{Introduction}

At National Institute of Metrological Research (INRIM) high Dc Resistance measurements in the range from $1 \mathrm{G} \Omega$ to $100 \mathrm{~T} \Omega$ are currently operated with two measurement methods. The first, based on a DC Voltage calibrator (DCV Cal) and a digital multimeter (DMM) can operate in the range $10 \mathrm{M} \Omega \div 1 \mathrm{~T} \Omega$ but is normally utilized at INRIM only from $1 \mathrm{G} \Omega$ [1]. With this method INRIM participated with satisfactory results at the comparison [2] performing the measurements at $1 \mathrm{G} \Omega$ and at the comparison [3] performing the measurements at $1 \mathrm{~T} \Omega$. With the second method, based on a modified Wheatstone bridge, operating at INRIM in the range from $100 \mathrm{G} \Omega$ to $100 \mathrm{~T} \Omega$ with two DCV Cals in the active arms of the bridge [1] INRIM participated at the comparison [3] performing the measurements at $1 \mathrm{~T} \Omega$ and at $100 \mathrm{~T} \Omega$ with satisfactory results. Nevertheless, recently INRIM acquired a high performance fully automated high resistance commercial bridge operating in the range from $100 \mathrm{k} \Omega$ to $10 \mathrm{P} \Omega$ whose operation mode is based on a similar principle [4]. This instrument could be very useful for its wide measurement field and because it allows to speed some technical operations as the measurement data processing, needed for the increasing amount of requested calibrations as it has an internal software that processes the data and gives out a simply file with all the needed information as ratio and resistance values and ratio standard deviation. In this paper a short description of the commercial bridge, a preliminary uncertainty evaluation of the measurement in the range $10 \mathrm{G} \Omega-10$ $\mathrm{T} \Omega$, the evaluation of the calibration of four high value Resistance Standards covering the above range with the commercial bridge and with the two validated INRIM high resistance methods to check the reliability and compatibility of the new bridge measurements, some considerations about the best measurement settle times, are given.

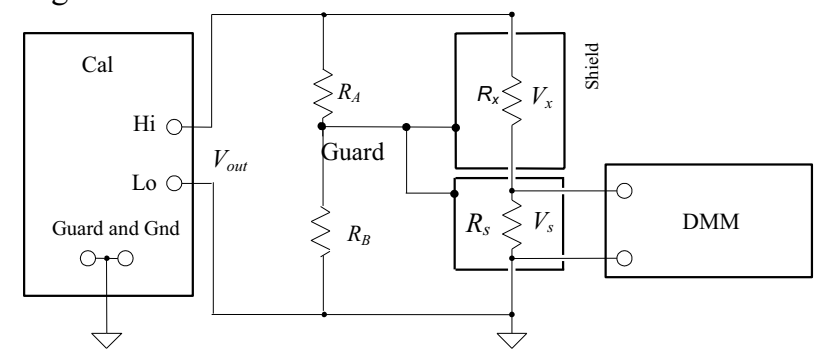

Figure 1. Scheme of the DMM-calibrator (DMM Cal) measurement method.

\footnotetext{
Corresponding author: f.galliana@inrim.it
} 


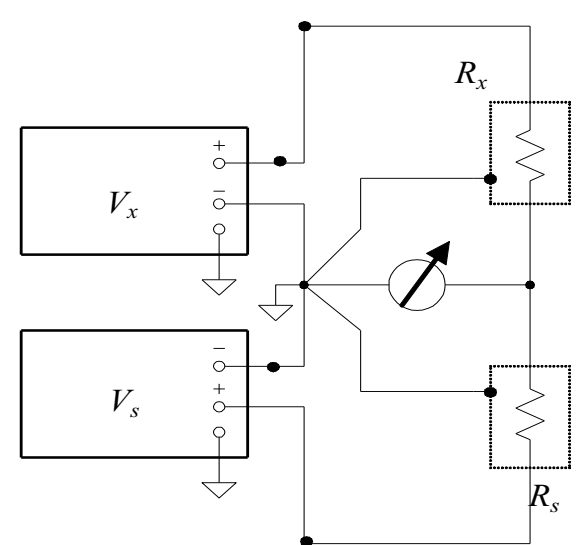

Figure 2. Scheme of the modified Wheatstone bridge (INRIM bridge).

\section{The high resistance commercial bridge}

The high performance fully automated Dual Source High Resistance bridge covers a wide calibration measurement field from $100 \mathrm{k} \Omega$ to $10 \mathrm{P} \Omega$ from $1 \mathrm{~V}$ to $1000 \mathrm{~V}$. It can compare two resistors in 10:1 or 100:1 ratios or make direct measurement as a teraohm-meter. It uses two programmable DC Voltage calibrators and a null detector controlled via IEE488 interface bus.

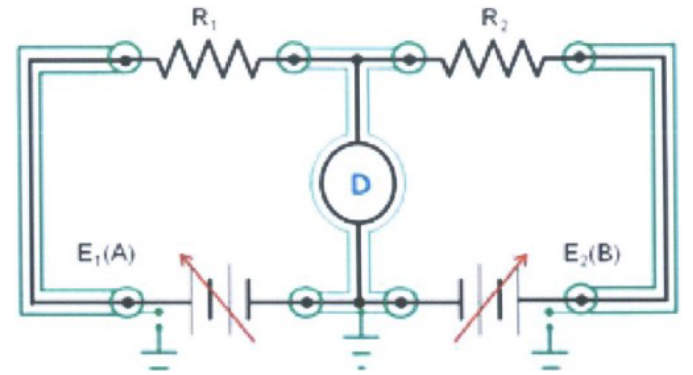

Figure3. Measurement scheme of the $\bar{h}$ igh Resistance bridge [4].

Also it is based on the Wheatstone bridge technique, the low impedance of the detector implies that the current flowing in each resistor connected to the bridge depends on the voltage applied on it by the calibrator. The voltage ratio is established so that the currents in the two resistors are in opposition and the bridge balance is reached when their difference is 0 . Nevertheless, the bridge does not reach the complete balance but only approaches it while the detector measures the unbalance relative to a circuit zero (Fig. 3). Uncertainty specifications of the bridge provided by the manufacturer are shown in Fig. 4 .

\begin{tabular}{|c|c|c|c|c|}
\hline \multirow{2}{*}{$\begin{array}{l}\text { Measurement } \\
\text { Range } \\
\text { (Ohms) }\end{array}$} & \multirow{2}{*}{$\begin{array}{l}\text { Applied } \\
\text { Voltage }\end{array}$} & \multicolumn{2}{|c|}{ Live Ratio Mode Uncertainty } & \multirow{2}{*}{$\begin{array}{c}\text { Direct } \\
\text { Measurement }\end{array}$} \\
\hline & & 1:1 and 10:1 Ratio & 100:1 Ratio & \\
\hline $100 \mathrm{k}$ to $1 \mathrm{M}$ & 1 to $100 \mathrm{~V}$ & $<7$ & $<20$ & $<80$ \\
\hline $1 \mathrm{M}$ to $10 \mathrm{M}$ & 1 to $100 \mathrm{~V}$ & $<7$ & $<20$ & $<80$ \\
\hline $10 \mathrm{M}$ to $100 \mathrm{M}$ & 10 to $1000 \mathrm{~V}$ & $<7$ & $<20$ & $<80$ \\
\hline $100 \mathrm{M}$ to $1 \mathrm{G}$ & 10 to $1000 \mathrm{~V}$ & $<7$ & $<20$ & $<80$ \\
\hline $1 \mathrm{G}$ to $10 \mathrm{G}$ & 10 to $1000 \mathrm{~V}$ & $<8$ & $<30$ & $<100$ \\
\hline $10 \mathrm{G}$ to $100 \mathrm{G}$ & 10 to $1000 \mathrm{~V}$ & $<10$ & $<30$ & $<200$ \\
\hline $100 \mathrm{G}$ to $1 \mathrm{~T}$ & 10 to $1000 \mathrm{~V}$ & $<15$ & $<50$ & $<400$ \\
\hline $1 \mathrm{~T}$ to $10 \mathrm{~T}$ & 100 to $1000 \mathrm{~V}$ & $<20$ & $<80$ & $<600$ \\
\hline $10 \mathrm{~T}$ to $100 \mathrm{~T}$ & 100 to $1000 \mathrm{~V}$ & $<30$ & $<100$ & $<2000$ \\
\hline $100 \mathrm{~T}$ to $1 \mathrm{P}$ & 100 to $1000 \mathrm{~V}$ & $<100$ & $<400$ & $<0.5 \%$ \\
\hline 1P TO 10P & 100 to $1000 \mathrm{~V}$ & $<100$ & $<600$ & $<3 \%$ \\
\hline
\end{tabular}

Figure 4. $2 \sigma$ type B accuracy specifications of the high Resistance commercial bridge.

As reported in the notes, these specifications cover only the type B uncertainty of the measurement ratios and do not take into account the uncertainty due to the reference resistor, the settle time, the repeatability of the ratio and the characteristics and environment conditions of the resistor under calibration. Nevertheless, starting from this table a first uncertainty budget regarding the calibration of four INRIM high value Standard Resistors in the range $10 \mathrm{G} \Omega-10 \mathrm{~T} \Omega$ was made. In Table 1 the uncertainty budget of the $1 \mathrm{~T} \Omega$ resistor at $1000 \mathrm{~V}$ is exploited.

Table 1. Preliminary uncertainty budget for the calibration of a $1 \mathrm{~T} \Omega$ standard resistor at $1000 \mathrm{~V}$ with the new commercial high resistance bridge in $10: 1$ ratio with a $100 \mathrm{G} \Omega$ resistor.

\begin{tabular}{|c|c|c|}
\hline Source & $\begin{array}{c}\text { Prob. } \\
\text { distr. }\end{array}$ & $\begin{array}{c}\mathbf{1} \boldsymbol{\sigma} \\
\text { uncertainty } \\
(\mu \Omega / \Omega)\end{array}$ \\
\hline $\mathrm{R}_{\mathrm{s}}$ & $\mathrm{B}$ & 17.0 \\
Repeatability & $\mathrm{A}$ & 3.6 \\
Connections & $\mathrm{B}$ & 5.8 \\
Balance & $\mathrm{B}$ & 17.3 \\
Stabilization & $\mathrm{B}$ & 20.2 \\
Sensitivity & $\mathrm{B}$ & 13.9 \\
Leakage & $\mathrm{B}$ & 5.8 \\
Bridge & $\mathrm{B}$ & 7.5 \\
\hline$u\left(R_{x}\right)$ & & 40.6 \\
$\boldsymbol{U}\left(\boldsymbol{R}_{\boldsymbol{x}}\right)$ & & $\mathbf{9 2 . 7}$ \\
\hline
\end{tabular}

In the $\mathrm{R}_{\mathrm{s}}$ component are included its calibration, environment effects, drift, voltage dependence uncertainty components. Nevertheless, this is only a preliminary budget and contacts with technicians of the bridge manufacturer are underway to establish a reliable criterion to evaluate the uncertainties of the measurements made with the bridge. The evaluated uncertainties in the range $10 \mathrm{G} \Omega \div 10 \mathrm{~T} \Omega$ at $100 \mathrm{~V}, 500 \mathrm{~V}$ and $1000 \mathrm{~V}$ for the calibration of four high performance INRIM Resistance Standards are summarized in Table 2. 
Table 2. Summary of the uncertainties in the calibration of four high performance INRIM standard resistors at three voltages with the new commercial high resistance bridge.

\begin{tabular}{|c|c|c|}
\hline Resistor & $\begin{array}{c}\text { Meas. } \\
\text { Voltage }\end{array}$ & $\begin{array}{c}\boldsymbol{U}\left(\boldsymbol{R}_{\boldsymbol{x}}\right) \\
(\mu \Omega / \Omega)\end{array}$ \\
\hline $10 \mathrm{G} \Omega$ & $100 \mathrm{~V}$ & 18 \\
& $500 \mathrm{~V}$ & 17 \\
& $1000 \mathrm{~V}$ & 17 \\
$100 \mathrm{G} \Omega$ & $100 \mathrm{~V}$ & 36 \\
& $500 \mathrm{~V}$ & 35 \\
& $1000 \mathrm{~V}$ & 34 \\
$1 \mathrm{~T} \Omega$ & $100 \mathrm{~V}$ & 96 \\
& $500 \mathrm{~V}$ & 97 \\
& $1000 \mathrm{~V}$ & 93 \\
$10 \mathrm{~T} \Omega$ & $500 \mathrm{~V}$ & 270 \\
& $1000 \mathrm{~V}$ & 220 \\
\hline
\end{tabular}

\section{Compatibility test between the INRIM methods and the high resistance bridge.}

A first compatibility test between the INRIM high resistance methods and the high resistance commercial bridge was made comparing the calibration values of four high performance high value standard resistors in the range $10 \mathrm{G} \Omega \div 10 \mathrm{~T} \Omega$. Table 3 shows the obtained results for each resistor at three voltages with the three methods along with their expanded uncertainties. The DMM-Cal method was involved in the measurements till up to $1 \mathrm{~T} \Omega$, while the measurements at $10 \mathrm{~T} \Omega$ were made only at $500 \mathrm{~V}$ and $1000 \mathrm{~V}$. The measurements with the two bridges were made in scaling 1:10 ratios. All the measurement results are expressed as relative deviation from nominal value.

Table 3. Comparison results between INRIM methods and the commercial for high resistance measurements. The measurement values are expressed as relative deviation from their nominal values.

\begin{tabular}{|c|c|c|c|c|c|c|c|}
\hline Resistor & $\begin{array}{l}\text { Voltage } \\
\text { (V) }\end{array}$ & $\begin{array}{c}\text { DMM } \\
\text { Cal } \\
\left(\times 10^{-6}\right) \\
\end{array}$ & $\begin{array}{c}\boldsymbol{U}_{\text {DMM-Cal }} \\
\left(\times 10^{-6}\right)\end{array}$ & $\begin{array}{c}\text { INRIM } \\
\text { Bridge } \\
\left(\times 10^{-6}\right)\end{array}$ & $\begin{array}{c}U_{\text {INRIM_bridge }} \\
\left(\times 10^{-6}\right)\end{array}$ & $\begin{array}{c}\text { Commercial } \\
\text { bridge } \\
\left(\times 10^{-6}\right)\end{array}$ & $\begin{array}{c}\boldsymbol{U}_{\text {comm_bridge }} \\
\left(\times 10^{-6}\right)\end{array}$ \\
\hline \multirow{3}{*}{$10 \mathrm{G} \Omega$} & 100 & 162.5 & 75 & 192.6 & 34 & 181.8 & 18 \\
\hline & 500 & 134.7 & 31 & 150.6 & 33 & 121.2 & 18 \\
\hline & 1000 & 110.5 & 34 & 102.6 & 35 & 99.2 & 17 \\
\hline \multirow{3}{*}{$100 \mathrm{G} \Omega$} & 100 & -69.0 & 70 & -75 & 71 & -44 & 36 \\
\hline & 500 & -47.9 & 98 & -67 & 68 & -79 & 35 \\
\hline & 1000 & -46.2 & 70 & -73 & 69 & -51 & 34 \\
\hline \multirow{3}{*}{$1 \mathrm{~T} \Omega$} & 100 & & & 1711 & 220 & 1624 & 96 \\
\hline & 500 & 1363 & 240 & 1430 & 100 & 1391 & 97 \\
\hline & 1000 & 1709 & 230 & 774 & 99 & 747 & 93 \\
\hline \multirow{2}{*}{$10 \mathrm{~T} \Omega$} & 500 & & & -16717 & 370 & -16882 & 270 \\
\hline & 1000 & & & -18294 & 360 & -18580 & 220 \\
\hline
\end{tabular}

In Figure $5-8$ the comparison results in graphical way are also shown.

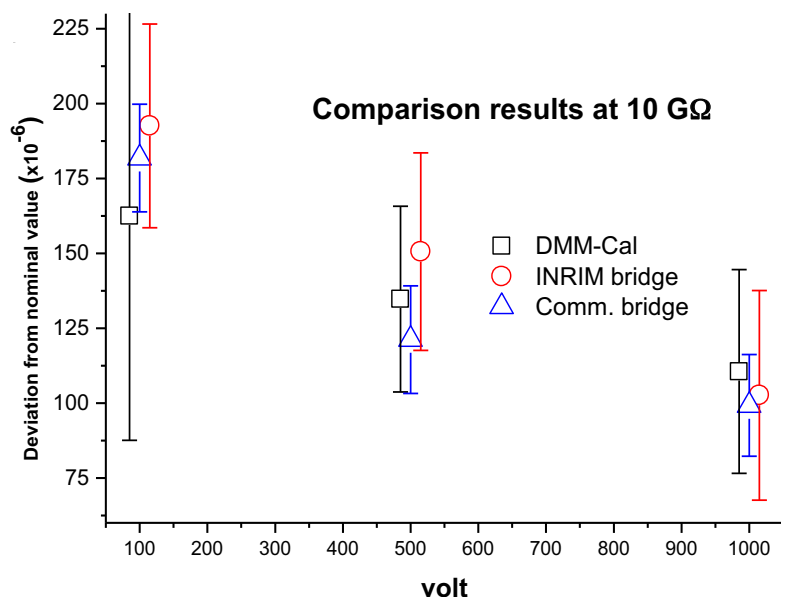

Figure 5. Compatibility results at $10 \mathrm{G} \Omega$.

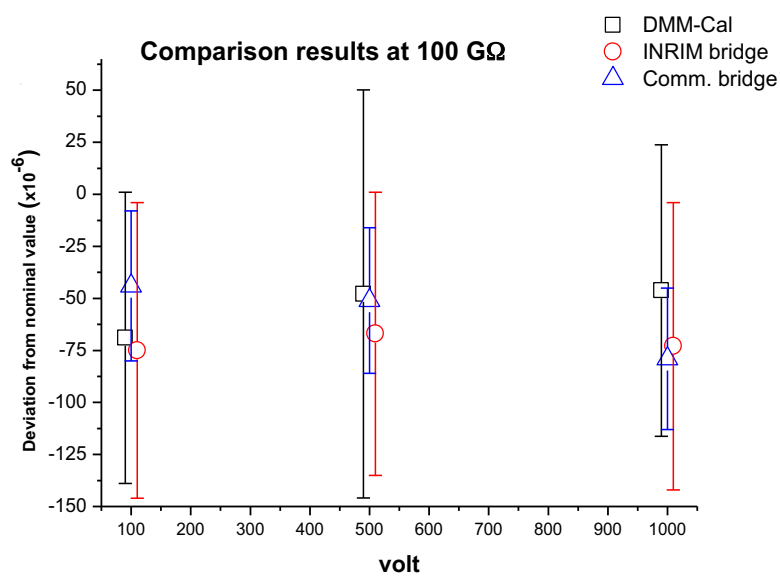

Figure 6. Compatibility results at $100 \mathrm{G} \Omega$. 


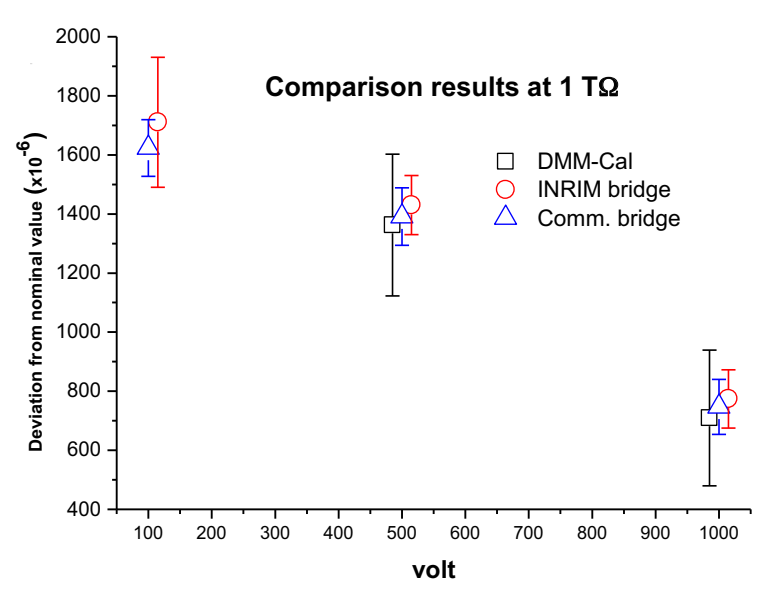

Figure 7. Compatibility results at $1 \mathrm{~T} \Omega$. The measurement at $100 \mathrm{~V}$ with the DMM-Calibrator method was not performed.

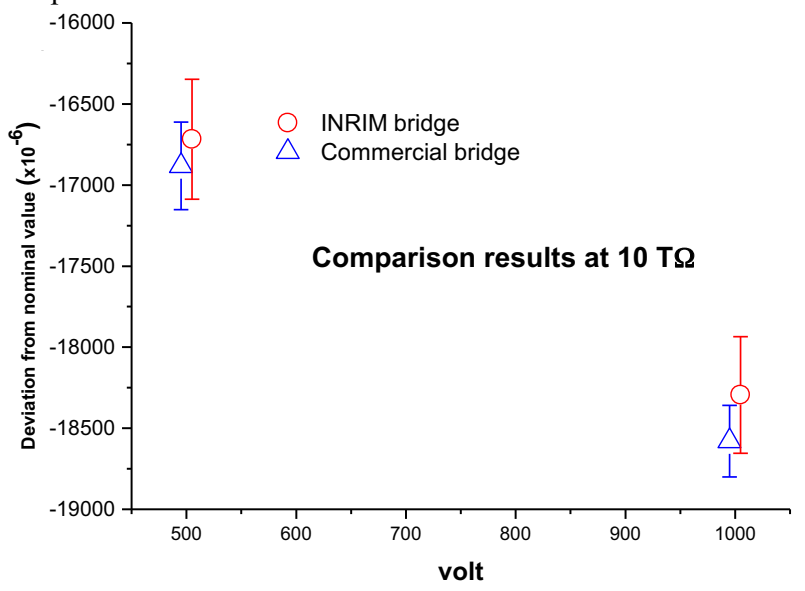

Figure 8. Compatibility results at $10 \mathrm{~T} \Omega$.

\section{Discussion and open problems.}

From Table 3 and figures 5-8 the first compatibility test of the measurement results between the INRIM methods and the commercial bridge in the range $10 \mathrm{G} \Omega-$ $10 \mathrm{~T} \Omega$ could be considered satisfactory. Concerning the measurements at $1 \mathrm{~T} \Omega$ and $10 \mathrm{~T} \Omega$ the best results were achieved setting on the commercial bridge settle times respectively of $180 \mathrm{~s}$ and $360 \mathrm{~s}$, much higher than suggested by the manufacturer instruction manual. Nevertheless, some problems still remain open. For example, the uncertainty budget has to be improved as it not clear from the user manual if the bridge specifications are always valid or limited to a definite time after DCV sources calibration, if specifications, drift, calibration uncertainties of the DCV sources and of the detector are taken into account, if the measurement criterion to evaluate the uncertainties reported in the specifications is correct. Another problem occurred at $100 \mathrm{~T} \Omega$ as the measurement with the commercial bridge resulted not compatible with that of the INRIM bridge or even not achievable both in 1:10 and 1:100 ratios and even in direct measurement. Then, the operation mode of the commercial bridge for values higher than $10 \mathrm{~T} \Omega$ as well its internal software have to be further investigated in particular when the deviation of the value of the resistor under calibration with respect its nominal value is significant.

\section{References}

1. Galliana, F. Capra P.P., Gasparotto E”, IEEE Trans. Instrum. Meas., 60,.3, pp.965-970, (2011).

2. Dziuba R. F. and Jarret. D. G., Metrologia, 39, p. 01 001, (2002).

3. Jeckelmann B. et al, METROLOGIA, 50, ISSN: 0026- 1394, (2013).

4. Jarrett D. G.” IEEE Trans. Instrum. Meas, 46 2, pp. 325-328, (1997). 